\title{
THE
}

$4-2009$

\section{Inter-Cohort Competition Drives Density Dependence and Selective Mortality in a Marine Fish}

Jameal F. Samhouri

Mark A. Steele

Graham E. Forrester

University of Rhode Island, gforrester@uri.edu

Follow this and additional works at: https://digitalcommons.uri.edu/nrs_facpubs

Terms of Use

All rights reserved under copyright.

\section{Citation/Publisher Attribution}

Samhouri, J. F., Steele, M. A. and Forrester, G. E. (2009), Inter-cohort competition drives density dependence and selective mortality in a marine fish. Ecology, 90: 1009-1020. doi: 10.1890/07-1161.1 Available at: http://dx.doi.org/10.1890/07-1161.1

This Article is brought to you for free and open access by the Natural Resources Science at DigitalCommons@URI. It has been accepted for inclusion in Natural Resources Science Faculty Publications by an authorized administrator of DigitalCommons@URI. For more information, please contact digitalcommons-group@uri.edu. 


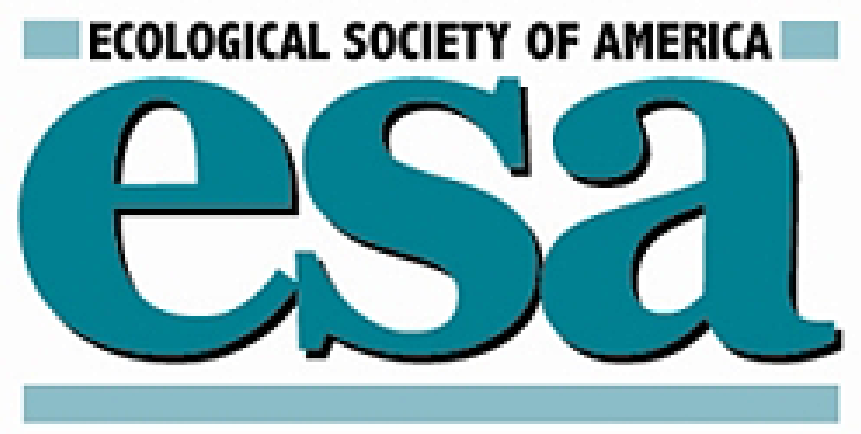

Inter-Cohort Competition Drives Density Dependence and Selective Mortality in a Marine Fish Author(s): Jameal F. Samhouri, Mark A. Steele and Graham E. Forrester

Source: Ecology, Vol. 90, No. 4 (Apr., 2009), pp. 1009-1020

Published by: Ecological Society of America

Stable URL: http://www.jstor.org/stable/25592588

Accessed: 21/03/2013 12:11

Your use of the JSTOR archive indicates your acceptance of the Terms \& Conditions of Use, available at http://www.jstor.org/page/info/about/policies/terms.jsp

JSTOR is a not-for-profit service that helps scholars, researchers, and students discover, use, and build upon a wide range of content in a trusted digital archive. We use information technology and tools to increase productivity and facilitate new forms of scholarship. For more information about JSTOR, please contact support@jstor.org. 


\title{
Inter-cohort competition drives density dependence and selective mortality in a marine fish
}

\author{
Jameal F. Samhouri, ${ }^{1,4}$ Mark A. Steele, ${ }^{2}$ and Graham E. Forrester ${ }^{3}$ \\ ${ }^{1}$ Department of Ecology and Evolutionary Biology, University of California, Los Angeles, California 90095-1606 USA \\ ${ }^{2}$ Department of Biology, California State University, 18111 Nordhoff Street, Northridge, California 91330-8303 USA \\ ${ }^{3}$ Department of Natural Resources Science, University of Rhode Island, Kingston, Rhode Island 02881 USA
}

\begin{abstract}
For organisms with complex life cycles, the transition between life stages and between habitats can act as a significant demographic and selective bottleneck. In particular, competition with older and larger conspecifics and heterospecifics may influence the number and characteristics of individuals successfully making the transition. We investigated whether the availability of enemy-free space mediated the interaction between adult goldspot gobies (Gnatholepis thompsoni), a common tropical reef fish, and juvenile conspecifics that had recently settled from the plankton. We added rocks, which provide refuge from predators, to one-half of each of five entire coral reefs in the Bahamas and measured the survival and growth of recent settlers in relation to adult goby densities. We also evaluated whether mortality was selective with respect to three larval traits (age at settlement, size at settlement, and presettlement growth rate) and measured the influence of refuge availability and adult goby density on selection intensity. Selective mortality was measured by comparing larval traits of newly settled gobies $(\leq 5 \mathrm{~d}$ postsettlement) with those of survivors $(2-3$ week postsettlement juveniles). We detected a negative relationship between juvenile survival and adult goby density in both low- and high-refuge habitats, though experimental refuge addition reduced the intensity of this density dependence. Juvenile growth also declined with increasing adult goby density, but this effect was similar in both low- and high-refuge habitats. Refuge availability had no consistent effect on selective mortality, but adult goby density was significantly related to the intensity of size-selective mortality: bigger juveniles were favored where adults were abundant, and smaller juveniles were favored where adults were rare. Given the typically large difference in sizes of juveniles and adults, similar stage-structured interactions may be common but underappreciated in many marine species.
\end{abstract}

Key words: age-structured interactions; coral reef fish; density dependence; early life history; enemyfree space; Gnatholepis thompsoni; inter-cohort competition; otoliths; phenotypic selection; refuge; shelter; stage-structured interactions.

\section{INTRODUCTION}

The complex life cycles of many organisms create the potential for interactions between conspecifics that vary greatly in size, age, and experience (e.g., insects, Cameron et al. 2007; amphibians, Eitam et al. 2005; aquatic invertebrates, McCauley and Murdoch 1987; scleractinian corals, Edmunds and Elahi 2007; marine algae, Schroeter et al. 1995; marine fishes, Bjornstad et al. 1999, Webster 2004). In such stage-structured populations, the strength of interactions between individuals in different age classes can exert a major influence on population dynamics (de Roos et al. 2003). Density-dependent interactions between stages can result from inter-cohort predation (i.e., cannibalism;

Manuscript received 16 July 2007; revised 16 May 2008; accepted 19 May 2008; final version received 16 July 2008. Corresponding Editor: M. H. Carr.

${ }^{4}$ Present address: Northwest Fisheries Science Center, National Marine Fisheries Service, NOAA Fisheries, 2725 Montlake Boulevard East, Seattle, Washington 98112 USA. E-mail: jameal.samhouri@noaa.gov
Murdoch 1994, Bjornstad et al. 1999), and also from competition for limiting resources, such as food (e.g., Eitam et al. 2005) or enemy-free space (e.g., Szabo 2002). In addition to causing numerical effects on population dynamics, interactions between age or size classes can lead to natural selection acting within populations (e.g., Claessen and Dieckmann 2002, Vandenbos et al. 2006) and across life stages (e.g., Vonesh and De la Cruz 2002).

These interactions among life stages are influenced by attributes of the current environment and the environment experienced during previous stages. For instance, the performance of larval individuals that have recently transitioned to adult habitat will be determined in part by environmental and demographic variation in the new habitat (e.g., food availability, population density; Relyea and Hoverman 2003, McCormick and Meekan 2007), in part by phenotypic variation generated in the larval environment (e.g., Searcy and Sponaugle 2001, Altwegg and Reyer 2003, Scott et al. 2007), and in part by the interaction between these factors. Though the 
number and characteristics of individuals successfully recruiting from larval to adult habitat can be a principal driver of overall population dynamics (e.g., Hamrin and Persson 1986, Searcy and Sponaugle 2001, Vonesh and De la Cruz 2002), the processes that govern success during transitions between life stages and habitats are complex and not fully understood.

If natural selection operates during transitions between life stages, phenotypic variation generated in one stage will have carry-over effects in the subsequent stage (Searcy and Sponaugle 2001, Beckerman et al. 2002, Gagliano et al. 2007). A burgeoning literature on marine organisms suggests that small differences between individuals in traits acquired in the larval stage can manifest effects on survival during the juvenile and adult stages (e.g., Litvak and Leggett 1992, Sogard 1997, Searcy and Sponaugle 2001, Marshall et al. 2003, Hoey and McCormick 2004, Gagliano et al. 2007, Vigliola et al. 2007, Hamilton et al. 2008). Such studies of marine fishes most often employ a longitudinal resampling experimental design, in which individuals from a single cohort are subsampled on multiple occasions to evaluate the fitness of larval characteristics (Anderson 1995). Phenotypic differences in back-calculated traits between successive collections indicate selective mortality (Sogard 1997). Though it is becoming clear that selective processes acting on larval traits are widespread among marine fishes, what drives variation in the direction and intensity of selection is not well understood. Specifically, to date few investigators have attempted to identify underlying selective processes (e.g., selective predation, resource competition) or to relate selective processes to variation in patterns of mortality observed across space and through time (but see McCormick and Hoey 2004, Holmes and McCormick 2006, McCormick and Meekan 2007).

Most studies of stage-structured interactions in fish populations focus on competition for food (e.g., de Roos and Persson 2003, Webster 2004) or cannibalism (e.g., Bjornstad et al. 1999). Here we test the hypothesis that competition for enemy-free space between adult and juvenile goldspot gobies (Gnatholepis thompsoni) determines demographic rates and selective mortality of juveniles during their first month of reef-based life. Specifically, we used a large-scale field experiment to ask: (1) Does refuge availability mediate the effects of adult gobies on the survival and growth of recently settled juveniles? And, (2) does competition for refuges between adults and juveniles affect phenotypic selection acting on the larval traits of new settlers?

\section{Methods}

\section{Study species and study area}

The goldspot goby is a common coral reef fish found throughout the wider Caribbean. Like the majority of marine reef fishes, goldspot gobies possess a planktonic larval stage (45-80 d) that ends when larvae settle to reefs (mainly June-October at our study sites), usually at a size of 9-12 mm standard length (SL) (J. F. Samhouri, M. A. Steele, and G. E. Forrester, unpublished data). Juveniles mature at $\sim 25 \mathrm{~mm} \mathrm{SL}$, adults can reach a maximum size of $\sim 60 \mathrm{~mm} \mathrm{SL}$, and most individuals live $<1$ year. Following settlement; goldspot gobies establish small stable home ranges that overlap with those of other gobies in areas of mixed sand and hard substrata. As a result, aggressive interactions among individuals of different sizes and ages are common (Forrester et al. 2006). Juveniles and adults forage on benthic invertebrates in the sand, unless threatened or attacked, in which case they seek temporary refuge from predators in crevices at the base of rocks, rubble, and live or dead coral (Fig. 1A). Refuge availability is particularly important to juvenile goldspot gobies because predation is the principal source of mortality (Steele and Forrester 2002).

We studied goldspot gobies at five reefs (Goby Spot, Rainbow, Square Rock, Tug and Barge, and Windsock Reefs) spread over $25 \mathrm{~km}$ near Lee Stocking Island, in the Exuma Cays, Bahamas $\left(23^{\circ} 46^{\prime} \mathrm{N}, 76^{\circ} 10^{\prime} \mathrm{W}\right.$; Appendix A: Fig. A1). These sites are located in shallow backreef areas (2-10 m depth) and possess 2500-15000 $\mathrm{m}^{2}$ of contiguous goby habitat. The reefs are isolated from each other and from other reefs by large expanses of sand and sea grass, making it extremely unlikely that adult gobies move between them. Consequently, we assumed that changes in population size occur only via larval settlement and deaths of resident juvenile and adult gobies. Juvenile gobies are exposed to a variety of potential predators, but in the Bahamas we most commonly observe predation by wrasses (Labridae) such as slippery dicks (Halichoeres bivittatus), yellowhead wrasses ( $H$. garnoti), and bluehead wrasses (Thalassoma bifasciatum; see Plate 1) (Steele and Forrester 2002; J. F. Samhouri, personal observations).

\section{Manipulation of shelter availability}

To test directly for effects of refuge availability on selective mortality and the interactions between adult and juvenile gobies, we manipulated the density of rocks and queen conch (Strombus gigas) shells at our five study sites. These rocks and shells, in addition to other natural crevices in the reefs, served as potential refuges for goldspot gobies. Though we did not quantify explicitly realized refuge use, gobies were observed in potential refuges within minutes of experimental rock/shell addition and consistently throughout the study (J. F. Samhouri, M. A. Steele, and G. E. Forrester, personal observations). Each reef was divided in half, and one-half was randomly selected for the experimental treatment while the other half of the reef remained unaltered as a control. We collected limestone rocks and conch shells $10-50 \mathrm{~cm}$ in diameter from the beaches of nearby cays and added them to the experimental side of each reef over the course of three years. Rocks and shells were distributed over the reef from the boat, and divers later returned to spread them relatively uniformly around the 


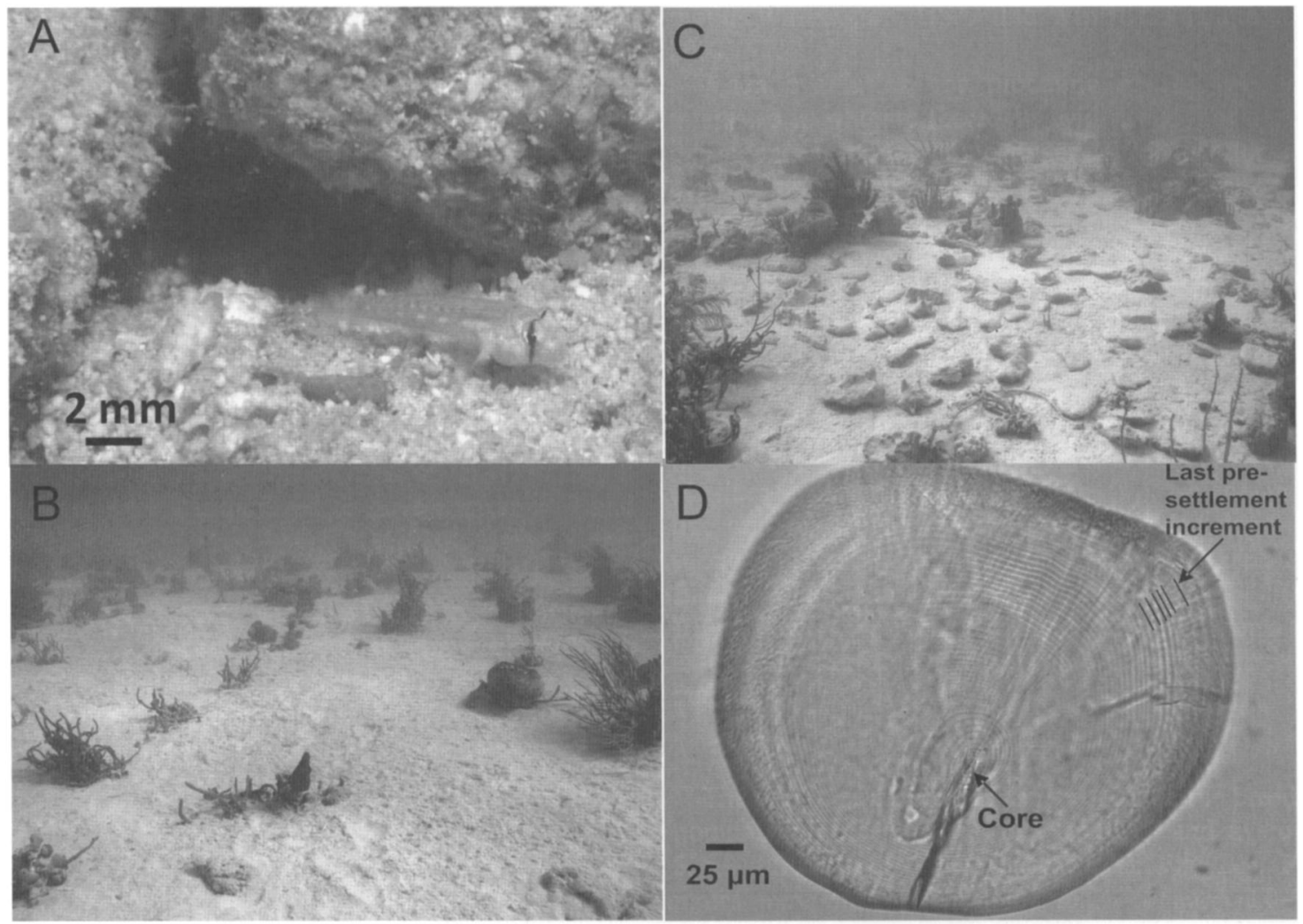

Fici. 1. (A) Photograph of a recently settled goldspot goby juvenile near a potential shelter site. (B) Photograph of low-shelter (control) habitat at one of the study sites. (C) Photograph of high-shelter (experimental) habitat at one of the study sites. Divers attempted to distribute the added limestone rocks and conch shells evenly around the experimental side of each reef. (D) Sagittal otolith of a 4-d postsettlement goldspot goby, depicting the location of the core and the last presettlement increment of the pelagic larval stage. Lines denote daily increments. (Photo credits: panels A-C, M. A. Steele; panel D, J. F. Samhouri).

experimental side of each reef (Fig. 1B, C). Shelter addition was completed at Square Rock Reef and Tug and Barge Reef in June 2003, at Goby Spot Reef and Windsock Reef in June 2004, and at Rainbow Reef in July 2005. We estimated the percent cover of rocks, shells, and coral, and the density of crevices potentially usable by gobies as refuges, on randomly placed $16-\mathrm{m}^{2}$ plots $\left(n=8\right.$ plots treatment ${ }^{-1} \cdot$ site $\left.^{-1}\right)$ before and after the experimental manipulations (June and November 2003, October 2004, and October 2005). These plots were placed around each of our study sites using a stratified, random design, and they adequately represented the spatial variation in potential refuge density and rock/ shell/coral cover on the reefs.

Before we added rocks and shells, the mean potential refuge density and percent cover of rock/shell/coral was statistically indistinguishable between control and experimental halves of reefs $(39.5$ vs. 39.3 potential refuges $/ \mathrm{m}^{2}$ and $16.9 \%$ vs. $13.7 \%$, respectively; paired $t$ test, $n=5$ : refuge density, $t=-0.06, P=0.96$; percent cover, $t=-1.01, P=0.40$; Appendix A: Fig. A2). After the manipulation, the potential refuge density and percent cover of rock/shell/coral was significantly higher on experimental halves of the reefs than on the control halves ( 39.9 vs. 68.2 potential refuges $/ \mathrm{m}^{2}$ and $13.6 \%$ vs. $20.8 \%$, respectively; paired $t$ test, $n=5$ : refuge density, $t$ $=3.50, P=0.025$; percent cover, $t=3.51, P=0.025$; Appendix A: Fig. A2). Hereafter, we refer to the experimental side of each reef as "high-shelter" habitat, and to the control side of each reef as "low-shelter" habitat, to indicate the relative availability of potential refuges.

This study focuses on patterns of mortality, growth, and phenotypic selection of recently settled goldspot gobies in high- and low-shelter habitats during the largest settlement events of 2004 and 2005 (in August of both years). Note that experimental treatments were established at four of our study sites in 2004 (all except Rainbow) and at all five sites in 2005 before the August settlement event occurred. For the purpose of analysis, we treated both sides of Rainbow Reef as low-shelter habitat in 2004.

\section{Juvenile goby mortality}

We calculated juvenile goby mortality rates by comparing the density of weekly settlement cohorts throughout August 2004 and 2005 (4 weeks/yr) to the density of surviving juveniles at the end of each 4-week 
period. The best way to estimate accurately unaltered goby settlement densities, along with the size structure and age/growth histories of recently settled gobies yet to experience reef-based selective mortality, is to minimize the effects of predation. Therefore, we monitored goby settlement rates to $1.5 \times 1.5 \mathrm{~m}$ plots $\left(n=5\right.$ plots $\cdot$ habitat ${ }^{-1} \cdot$ site $\left.^{-1}\right)$, each covered by a plastic mesh predator-exclusion cage (5-mm openings). Settlement plots were placed using a stratified, random design, and the cages on each plot excluded predatory fishes but not goby settlers. We used hand nets to collect and remove gobies from the settlement plots once each week. At the time of each collection, we distinguished fish that settled in the preceding week from older residents using a known relationship between size and age (J. F. Samhouri and M. A. Steele, unpublished data). Previous work demonstrated that weekly sampling from caged plots provides an estimate of settler density comparable to that obtained with daily sampling (Steele and Forrester 2002).

At the end of August in 2004 and 2005, we made visual counts of gobies within the $16-\mathrm{m}^{2}$ quadrats $(n=8$ plots treatment ${ }^{-1} \cdot$ site $^{-1}$ ) used to assess potential refuge density and rock/shell/coral cover (an impending hurricane prevented us from surveying Square Rock in 2004). In each plot, the length of every goby was judged by a single diver and assigned to one of nine 5-mm size (SL) classes. Visual estimates of size were accurate within 2 $\mathrm{mm}$ SL of actual size, based on regular field trials in which gobies $(n>200)$ were captured and measured after their length had been estimated visually (M. A. Steele, unpublished data).

We measured the instantaneous per capita mortality rate between the day of settlement and the late August censuses for juvenile gobies using the following equation:

$$
X_{T}=\sum_{i=1}^{4} x_{t_{i}} e^{-\left(T-t_{i}\right) m} .
$$

The calculation focused on the estimated density of gobies in each cohort $\left(x_{i}\right)$ settling to a particular site and habitat during each of the four weeks preceding the plot censuses. We made the simplifying assumptions that (1) all settlers arrived exactly at the midpoint of each week (so $t_{i}$ is the day on which the $i$ th cohort settled), and (2) all individuals experienced the same mortality rate $m$ from the day of settlement until the day of the August plot census. We used a known relationship between size and age (J. F. Samhouri and M. A. Steele, unpublished data) to determine the density of gobies censused at the end of August $\left(X_{T}\right)$ that had settled in the preceding four weeks and survived to be counted on day $T$. We estimated juvenile mortality during the first 30 days after settlement by solving Eq. 1 iteratively.

We used these mortality data to test for effects of intra- and inter-cohort competition. Unlike many studies of juvenile mortality rate in coral reef fishes (reviewed by Hixon and Webster 2002), we performed our research on natural continuous reefs where multiple age and size cohorts of gobies overlap (see also Webster and Hixon 2000, Carr et al. 2002, Webster 2004, Sandin and Pacala 2005, Anderson et al. 2007). Adult and juvenile goldspot gobies behave similarly in that they forage in patches of sand and retreat to the same refuges under rocks or coral when threatened by predators, but adult gobies are much larger than recently settled juveniles (2.5-5-fold larger in SL) and more aggressive (Forrester et al. 2006). Adults should thus have a much larger competitive weight (sensu Parker and Sutherland 1986) than juveniles in terms of the amount of space they occupy in refuges. To evaluate the relative evidence for inter-cohort (adult or older juvenile), intra-cohort (settler), or combined inter- and intra-cohort (overall density) effects on juvenile goby mortality, we compared the weight of evidence for four different models using four different goby density metrics (settlers, $\leq 12 \mathrm{~mm}$ SL; older juveniles, 15-24 mm SL; adults, $\geq 25 \mathrm{~mm} \mathrm{SL}$; overall, all size classes) as predictors of juvenile mortality (Appendix B). Based on Akaike's Information Criterion corrected for small sample sizes ( $\mathrm{AIC}_{\mathrm{c}}$; Burnham and Anderson 2002), the model including adult goby density was considerably superior to the others we tested (Appendix B: Table B1). Therefore, below we focus the juvenile mortality analysis entirely on the effects of adult goby density.

We used ANCOVA to test for a difference in the relationship between mortality rate of recent settlers and adult goby density in low- vs. high-shelter habitats. This model included adult goby density as a covariate, along with experimental treatment (low-shelter or high-shelter habitat) and year (2004 or 2005) as fixed effects. A positive correlation between the juvenile per capita mortality rate and adult goby density would indicate density dependence. In this statistical model and others in which adult goby density appears as a covariate, if a shortage of refuges is the mechanism of density dependence, then this density dependence should be reduced or eliminated where refuges were abundant. Such an effect would be indicated in the ANCOVA by a significant interaction between goby density and shelter availability. Because goldspot gobies live on average for $\leq 1$ year (M. A. Steele, unpublished data), and individuals used in the 2004 experiment were different from the individuals used in the 2005 experiment, we used average goby density for each site-year-habitat combination as the unit of replication in our analyses. In this analysis and others that follow, we included year as a fixed effect to determine if the results were similar in the two years of the study, though this choice limits our ability to make inferences about any other years. For all of the analyses, we checked that our data met assumptions of normality and homogeneity of variance, and then used post hoc pooling procedures to sequentially remove nonsignificant interaction terms, starting with the highest-order interactions (Winer et al. 1991). 
To determine if predators responded to the shelter manipulation directly and if predator density was related to juvenile goby mortality rate, a single diver counted the number of slippery dicks, yellowhead wrasses, and bluehead wrasses $>25 \mathrm{~mm}$ SL in the same $16-\mathrm{m}^{2}$ plots in which goby density and potential refuge density were assessed (August 2004 and 2005). We compared the average wrasse density per $16-\mathrm{m}^{2}$ plot for each site-year-habitat combination using two-way ANOVA, with experimental treatment and year as categorical effects. We also used ANCOVA to test for an effect of predator density, experimental treatment, and year on juvenile goby mortality rate.

\section{Juvenile goby growth and natural selection on larval traits}

To examine the effects of the shelter manipulation on juvenile goby growth rate and on selective mortality of juvenile gobies with particular larval traits, we collected two groups of gobies from low-shelter and high-shelter habitats at Windsock Reef in 2004, Goby Spot Reef in 2004 and 2005, and Rainbow Reef in 2005. We used hand nets to collect an initial group of recent settlers (i.e., preselection group) over a one-week period during the peak summer settlement event (August) in each year. Initial group collections were made exclusively from the settlement cages described previously in 2004 , and from a combination of settlement cage collections and collections made by roving divers over open reef in 2005. We returned to our study sites to sample surviving individuals (i.e., post-selection group) from these cohorts after 2-3 weeks. Because our sites were large, and each was occupied by many thousands of gobies, these collections had a negligible impact on overall goby population density. After collection, gobies were preserved in $95 \%$ ethanol.

We obtained estimates of juvenile goby larval traits and postsettlement growth rate using the permanent record of age, relative size-at-age, and growth rate contained within their otoliths. Growth rings correspond to daily increments in otolith growth in this species, as verified using a standard alizarin marking technique (M. A. Steele, unpublished data). In the laboratory, we measured the SL of preserved gobies and extracted their sagittal otoliths. The otoliths were placed in immersion oil for $\geq 30 \mathrm{~d}$ to clear and facilitate interpretation. Otoliths were viewed using an Olympus compound microscope (200× magnification with dual polarizing filters). Increment measurements were made along the longest axis of the otolith, from the core to the outermost complete ring, using image analysis software (Image Pro Plus 4.5, Media Cybernetics, Bethesda, Maryland, USA). We identified the time of settlement following Sponaugle and Cowen (1994), and based on our own comparison of larvae and reef-collected goby settlers (M. A. Steele, unpublished data; Fig. 1D). All otoliths were read twice by one person (J. F. Samhouri) and unclear or abnormally shaped otoliths were discarded.
To study selective mortality, we measured three phenotypic traits for each individual: age at settlement (i.e., pelagic larval duration or PLD; d), size at settlement (otolith length measured from the core to the settlement mark; $\mu \mathrm{m}$ ), and presettlement growth (mean width of the last 14 increments prior to settlement; $\mu \mathrm{m} / \mathrm{d})$. For small goldspot gobies (8.5-15 $\mathrm{mm}$ SL), body length and otolith length show a linear relationship $\left(n=226, r^{2}=0.77\right)$, suggesting that otolith increment width is a reasonable proxy for somatic growth and otolith length is a reasonable proxy for somatic length. To avoid problems with back-calculating somatic traits from otoliths, however, we performed statistical analyses on otolith traits as a relative measure of growth and size.

We determined group membership (initial vs. survivor) based on each individual's postsettlement age and back-calculated settlement date. This approach revealed that our collections of newly settled gobies consisted of individuals that arrived to our study sites over a twoweek window of peak settlement in each year. We defined the initial group as individuals aged 0-5 d postsettlement (2004, $n=141 ; 2005, n=164$; Appendix C: Table C1). Larval traits of individuals in the initial group collected from settlement cages did not differ significantly from those of individuals collected by roving divers. We included individuals in the survivor group only if they settled within the same two-week window as the initial group. As a result, survivors consisted of individuals aged 14-25 d postsettlement (2004, $n=85$; 2005, $n=132$; Appendix C: Table C1). Thus, we examined selection on larval traits that occurred on the reef over a minimum of $10 \mathrm{~d}$ and a maximum of $26 \mathrm{~d}$ following settlement.

Preliminary inspection of larval traits (size at settlement, age at settlement, and presettlement growth rate) collected from different sites and years revealed significant differences among the initial groups. Larval traits, however, did not differ among initial group individuals collected from low- and high-shelter habitats within a site. Consequently, we tested for directional selection, i.e., whether mean larval trait values shifted from the initial to the survivor group, at each site separately. For each site, we first used MANOVA to test the null hypothesis that larval traits (standardized to zero mean and unit variance) were not affected by experimental treatments (low-shelter or high-shelter habitat), group membership (initial or survivor), or their interaction. In cases where Pillai's trace and its $F$ approximation indicated significance, we used univariate tests (ANOVA) to identify which larval traits were responsible for the differences (Scheiner 2001). For the univariate tests, a significant interaction would be expected if the direction or strength of selection on the larval trait depended on the habitat in which the gobies occurred. Alternatively, selection that was consistent between habitat treatments would be revealed by a significant difference between initial and survivor groups. 


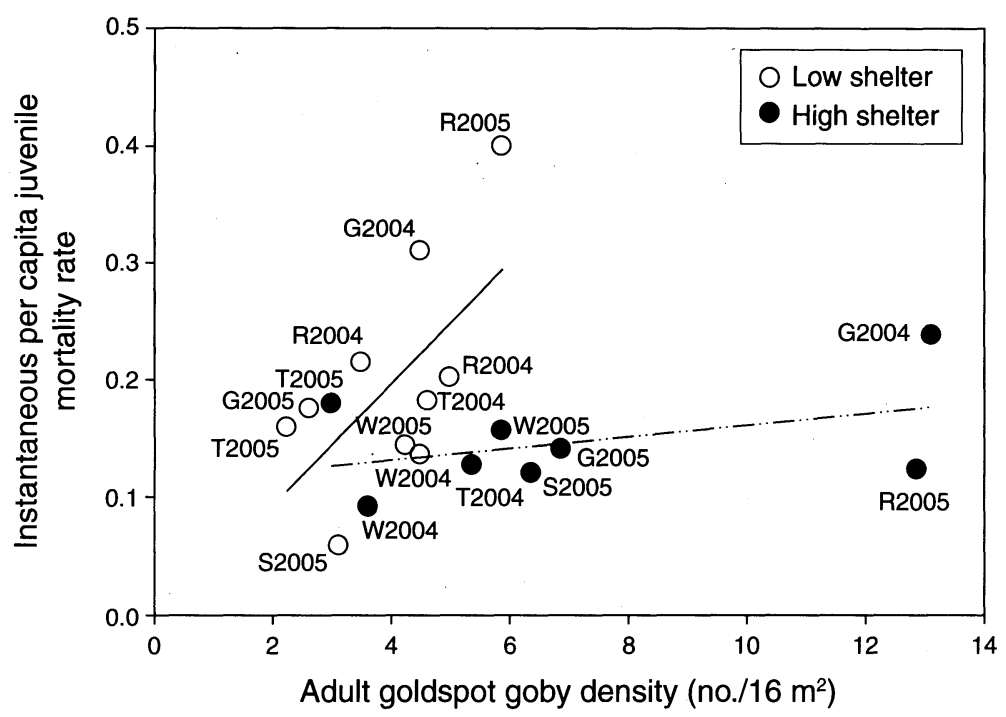

Fig. 2. Experimental evidence that mortality rate of recently settled goldspot gobies $(\leq 30 \mathrm{~d}$ postsettlement age $)$ is more strongly related to the density of adult goldspot gobies in low-shelter habitats (control treatment) than in high-shelter habitats (experimental treatment). Data are from Goby Spot (G2004, G2005), Rainbow (R2005), Square Rock (S2005), Tug and Barge (T2004, T2005), and Windsock (W2004, W2005) Reefs.

We also measured the intensity of linear selection $\left(S_{i}\right)$ on the $i$ th larval trait $\left(z_{i}\right)$ as the difference in trait means before and after selection standardized by the standard deviation before selection (Endler 1986):

$$
S_{i}=\frac{\bar{z}_{i, \text { after }}-\bar{z}_{i, \text { before }}}{S D_{\text {before }}} .
$$

We examined the relationship between $S_{i}$ and adult density for each larval trait. We did not test for a relationship between $S_{i}$ and other goby density metrics because adult density was the most likely predictor of juvenile mortality rate (Appendix B), an important component of fitness, making adults the most plausible selective agent. In addition, for this analysis and the growth rate analysis that follows, our sample sizes ( $n=$ 8) were restricted, prohibiting us from employing a model comparison approach like the one we used in the analysis of juvenile mortality (Appendix B). As before, we used average adult goby density (from late August plot censuses) for each site-year-habitat combination as the unit of replication in our analyses. We used ANCOVA to test for the effects of experimental treatment, year, and adult goby density on $S_{i}$. Due to our limited sample sizes, we could not test the complete ANCOVA model that included the three-way interaction between experimental treatment, year, and adult goby density, but we were able to test all two-way interactions. Our main goals were to determine if selection intensity was correlated with adult goby density, and whether the relationship between adult goby density and selection intensity was affected by the habitat in which the gobies occurred. This latter effect would be indicated by a significant interaction between experimental treatment and adult goby density.

Finally, we tested for an effect of the experimental treatments on the relationship between adult goby density and the postsettlement growth rate of juveniles. We determined the average daily otolith growth rate following settlement onto the reef from the otoliths of individuals collected as part of the survivor groups described previously (postsettlement growth rate; $\mu \mathrm{m} / \mathrm{d}$ ). As in the analysis of juvenile goby mortality rate, we used an ANCOVA that included adult goby density as a covariate, along with experimental treatment and year as categorical effects. We also tested for an effect of predator density, experimental treatment, and year on juvenile goby growth rate using ANCOVA. In neither case could we test the three-way interaction between experimental treatment, year, and adult goby or predator density, but we were able to test all two-way interactions. As before, we used average adult goby density or average wrasse density (from late August plot censuses) for each site-year-habitat combination as the unit of replication in our analyses.

\section{RESULTS}

We detected a positive correlation between the mortality rate of juvenile goldspot gobies during their first month on the reef and the density of adult conspecifics. This relationship was strong in low-shelter habitats, but less so in high-shelter habitats, as indicated by a significant experimental treatment by adult density interaction in the ANCOVA $\left(F_{1,13}=4.77, P=0.048\right.$; Fig. 2). This result suggests that the availability of potential refuges mediated the strength of a negative, 


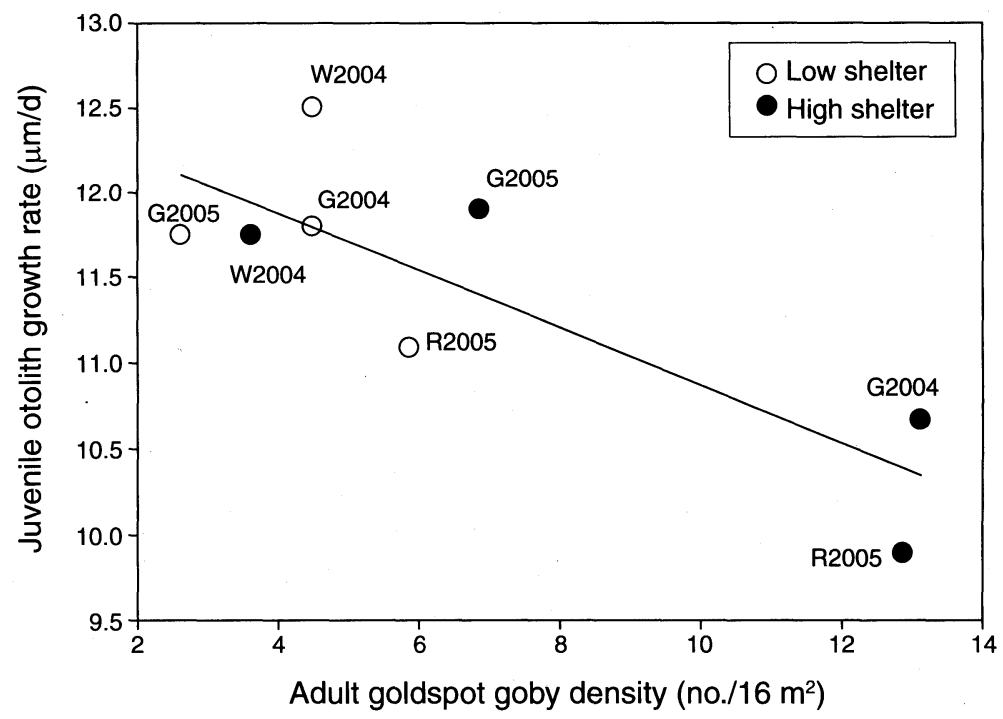

FIG. 3. Negative relationship between mean daily otolith growth rate of recently settled juvenile goldspot gobies (14-25 d postsettlement age) and mean adult goldspot goby density. Data are from low-shelter (control treatment) and high-shelter (experimental treatment) habitats at Goby Spot (2004, 2005), Rainbow (2005), and Windsock (2004) Reefs. Points are labeled as in Fig. 2.

and density-dependent, interaction between adult and juvenile gobies. While the two greatest mortality rates (low-shelter) had high influence on the significant interaction displayed in Fig. 2, they correspond to two different sites in two different years (Goby Spot 2004 and Rainbow 2005). Additionally, our manipulation caused adult goby densities in high-shelter habitat to exceed adult densities in low-shelter habitat by as much as 2.5-fold (Appendix A: Fig. A3-A7). Therefore, it is probable that we would have detected a relationship between adult density and juvenile mortality in highshelter habitat if one existed, but the slope of this relationship was indistinguishable from zero $(P=0.35$; Fig. 2). Juvenile mortality rate did not differ significantly between years $\left(F_{1,13}=0.07, P=0.79\right)$.

Juvenile postsettlement growth rate also was negatively correlated with adult goby density $\left(F_{1,4}=7.90, P=\right.$ 0.048; Fig. 3). However, there was no evidence that this density-dependent effect was mediated by potential refuge abundance (treatment $\times$ adult density, $F_{1,1}=$ 1.447, $P=0.44$ ), though there was little scope to detect such an interaction given the limited sample sizes $(n=8)$ in this analysis (power $=0.05$; Fig. 3). The two slowest growth rates displayed in Fig. 3 exert considerable influence over the significant adult density effect, but as in Fig. 2, these points correspond to two different sites in two different years (Goby Spot 2004 and Rainbow 2005). There was no effect of the shelter manipulation on juvenile growth rate $\left(F_{1,4}=0.0029, P=0.92\right)$, nor was there a difference in growth rates between years $\left(F_{1,4}=\right.$ $0.1853, P=0.43$ ).

Predator densities tended to be greater in high-shelter habitat $(7.55 \pm 1.52$ wrasses; mean $\pm \mathrm{SE})$, where juvenile goby mortality was on average lower than in low-shelter habitat (4.36 \pm 0.87 wrasses) (Appendix A: Fig. A3-A7). However, this difference was not statistically significant $\left(F_{1,14}=3.34, P=0.09\right)$. Additionally, there was no significant difference in predator densities between years $\left(F_{1,14}=0.0086, P=0.93\right)$. Furthermore, predator density was not significantly related to juvenile goby mortality $\left(F_{1,14}=3.19, P=0.10\right)$ or to juvenile postsettlement growth rate $\left(F_{1,4}=0.0385, P=0.85\right)$.

We compared the mean values for size at settlement, age at settlement, and presettlement growth rate between the initial and survivor groups for a total of four cohorts collected from Windsock Reef (2004), Goby Spot Reef (2004 and 2005), and Rainbow Reef (2005). Overall, selective mortality was not consistent across space or through time with respect to the shelter manipulation (Appendix C). Comparison of the three larval traits using MANOVA suggested that gobies did not experience significant selective mortality at Goby Spot Reef in either year (2004, Pillai's trace, $F_{9,399}=$ $1.08, P=0.38 ; 2005$, Pillai's trace, $F_{9,468}=0.8533, P=$ $0.57)$. In contrast, we did detect selective mortality at Windsock Reef (Pillai's trace, $F_{9,255}=2.05, P<0.035$ ) and at Rainbow Reef (Pillai's trace, $F_{9,396}=2.04, P<$ $0.034)$.

Though gobies occurring at Windsock and Rainbow Reefs experienced phenotypic selection on size and age at settlement (Appendix C: Fig. C1), the strength and direction of selection did not vary predictably for either trait or with shelter availability (Appendix C). Surviving gobies (14-25 d postsettlement) collected from lowshelter habitat at Windsock Reef were on average older at the time of settlement than those in the initial group ( $0-5 \mathrm{~d}$ postsettlement), whereas survivors collected from high-shelter habitat were younger at the time of 

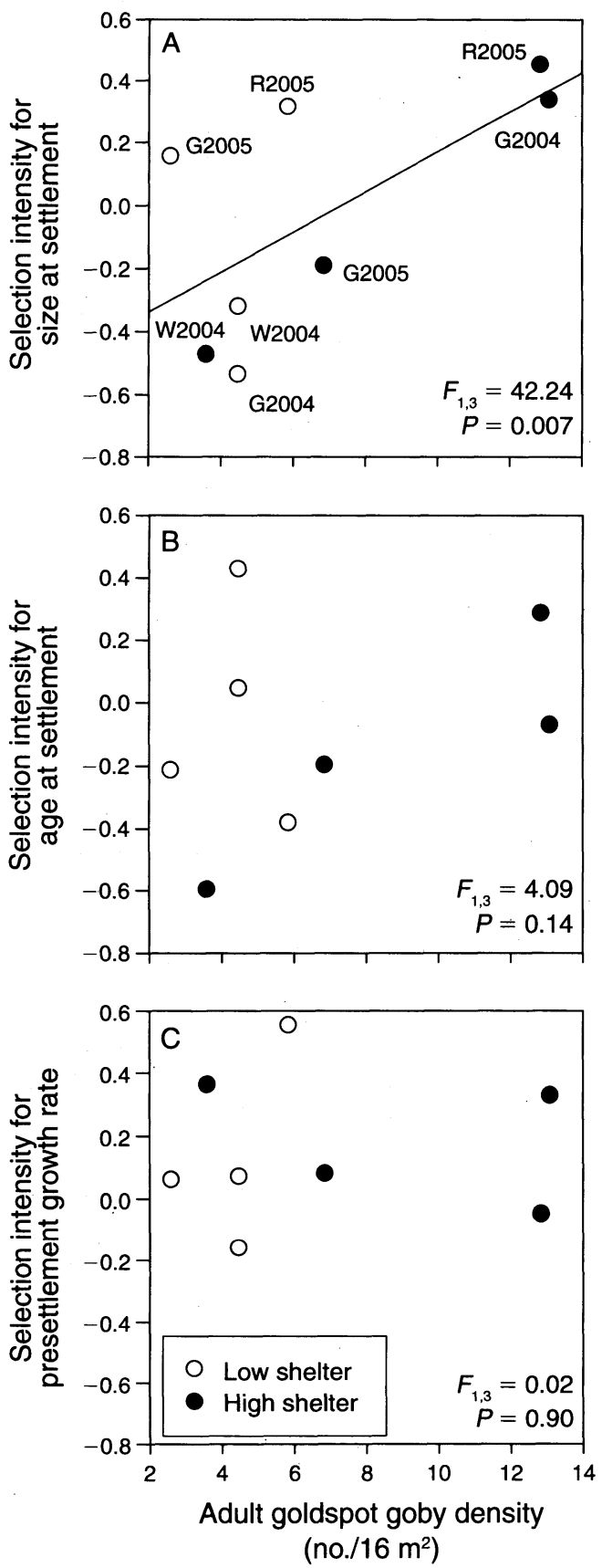

FIG. 4. Relationships between selection intensity on traits of recently settled juveniles and mean adult goldspot goby density. Juvenile traits are otolith-based (A) size at settlement, (B) age at settlement, and (C) presettlement growth rate. Data are from low-shelter (control treatment) and high-shelter (experimental treatment) habitats at Goby Spot (2004, 2005), Rainbow (2005), and Windsock (2004) Reefs. Points in (A) are labeled as in Fig. 2. Results of ANCOVA testing for an effect of adult goldspot goby density on selection intensity are also displayed.

settlement (Appendix C: Fig. C1, Table C1). At Rainbow Reef, the mean age at settlement of survivors collected from low-shelter habitat was lower than that of the initial group. In contrast, the mean age at settlement of survivors was higher than that of the initial group in high-shelter habitat (Appendix C: Fig. C1, Table C1). For size at settlement, gobies in the survivor group were relatively small at the time of settlement at Windsock Reef in both low- and high-shelter habitat (Appendix C: Fig. C1, Table C1). At Rainbow Reef, gobies that were on average bigger at the time of settlement were overrepresented in the survivor group collected in both low- and high-shelter habitats (Appendix C: Fig. C1, Table C1). Presettlement growth rate did not differ between initial and survivor groups in either low-shelter or high-shelter habitats for any of the four cohorts.

Selection intensity on size at settlement was significantly and positively related to adult density $\left(F_{1,3}=\right.$ 42.24, $P=0.007$ ). That is, bigger juveniles were more likely to survive in locations where adult density was high and smaller juveniles were more likely to survive in locations where adult density was low (Fig. 4A). However, because this relationship is driven primarily by two data points from the high-shelter treatment, it should be interpreted with some caution. There was also a significant experimental treatment by year interaction $\left(F_{1,3}=14.90, P=0.031\right)$ because selection intensity for size at settlement was statistically indistinguishable in low- and high-shelter habitats in 2004, but differed between habitats in 2005. There was no significant effect of adult goby density, treatment, or year on selection intensity for age at settlement or presettlement growth rate $(P>0.1$; Fig. 4B, C). Adult density did not interact significantly with treatment or year effects for any of the three larval traits examined.

\section{Discussion}

For many organisms with complex life cycles, regulatory density dependence occurs during the early life history stages (e.g., Petranka 1989, Hixon and Webster 2002, Vonesh and De la Cruz 2002). Densitydependent mortality of recently settled juvenile reef fishes appears to be particularly widespread. Recent work demonstrates that in several species of reef fishes, the cause of density-dependent mortality is intra-cohort competition for enemy-free space (Holbrook and Schmitt 2002, Forrester and Steele 2004, Hixon and Jones 2005). Fewer investigators have examined how the density of older age classes influences survival of younger juveniles (but see Jones 1987, Schmitt and Holbrook 1999, Webster and Hixon 2000, Webster 2004, Wilson 2005). The results presented in this study indicate that competition between adults and juveniles for enemy-free space leads to density-dependent mortality of recently settled goldspot gobies. This study thus provides compelling evidence for what previous research suggested could be a major source of population regulation for this species (Forrester et al. 2006).

While we did not investigate it directly, the mechanism for the density dependence we observed could be adult aggression toward juveniles, intraspecific priority effects, or both. All size and age classes of goldspot 


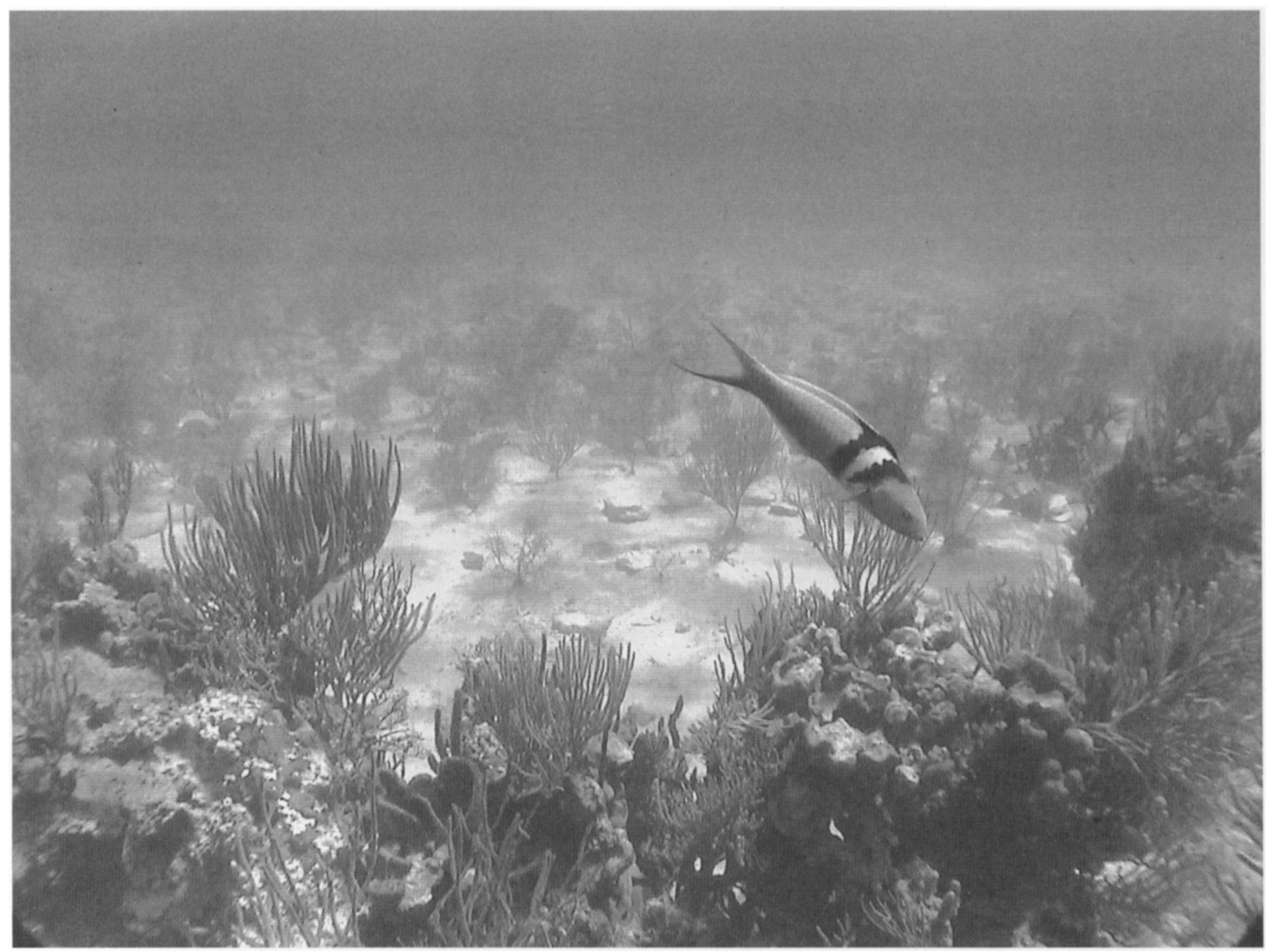

Plate 1. A potential goldspot goby predator, the bluehead wrasse $(\sim 12 \mathrm{~cm}$ standard length), at Goby Spot Reef, Exuma Cays, Bahamas. Photo credit: Kerry J. Nickols.

gobies retreat to crevices under rocks and coral when threatened or attacked (Steele and Forrester 2002). Encounters with predators likely increase for individuals engaged in disputes over limited shelter space (Shulman 1985), and such aggressive interactions climb with goby density (Forrester et al. 2006). In areas with ample shelter, contests for available enemy-free space are probably less frequent and predator encounters are less likely to result in prey capture. We believe that the proximate cause of juvenile deaths in this study was predation (Steele and Forrester 2002), and our results imply that this interaction was ultimately mediated through density-dependent competitive effects of adults on juveniles (Hixon and Jones 2005). However, we found no correlation between juvenile mortality rates and predator density, probably in part because predators tended to be more abundant where potential refuges from them were more abundant (the shelter-addition treatment areas). Because our data represent temporal snapshots of predator densities, though, they may not necessarily predict encounter rates of predators with gobies.

Adult aggression toward juveniles may also explain the observed decline in juvenile goldspot goby growth rate with increasing adult density. Because experimental addition of rocks did not mediate the strength of this density-dependent growth, aggressive encounters that influence juvenile growth probably occurred during foraging bouts away from refuges (also see Forrester et al. 2006). That is, the shelter addition experiment may have done nothing to ameliorate agonistic interactions that occurred while gobies were feeding. Density dependence induced by behaviorally mediated asymmetric competition between age classes may be a common feature of size-structured populations (e.g., Post et al. 1999, Eitam et al. 2005, Vandenbos et al. 2006), including reef fishes (Forrester 1990, Forrester 1991, Schmitt and Holbrook 1999, Webster 2004).

Intraspecific priority effects due to asymmetries in competitive weight are known to occur in a variety of other animals (e.g., insects, Crowley et al. 1987; amphibians, Eitam et al. 2005; freshwater fishes, Fraser and Sise 1980; marine fishes, Szabo 2002), and may offer another explanation for the negative effects of adults on juvenile survival in low-shelter habitat. Adults have a greater competitive weight (sensu Parker and Sutherland 1986) than juveniles because a single adult monopolizes space sufficient for many juveniles, while juveniles can shelter in crevices that are too small for adults. Consequently, in habitats where we did not augment 
refuge availability, adult gobies may have claimed the relatively few areas of high crevice density and thereby preempted juveniles from obtaining refuges. This preemption may have occurred via earlier territory establishment (i.e., earlier settlement to the reef) or via faster retreat to unguarded crevices during predator attacks. It remains unclear whether such intraspecific priority effects vary in importance through time because our study was conducted during the peak period of settlement in both 2004 and 2005, and when adult population densities were high. Goby larvae arriving to reefs during other times of the year when adult densities are lower may not suffer to the same degree from intercohort competition.

Experimental addition of potential refuges to goby habitat did not lead to consistent patterns of selective mortality. That is, natural selection acting on phenotypic traits acquired during the larval stage (i.e., size at settlement, age at settlement, and presettlement growth rate) did not vary in a predictable way with the supply of shelter. Though we observed a selective advantage for individuals that were older and larger at settlement (Rainbow 2005 high-shelter habitat), we also observed the reverse trend (Windsock 2004 high-shelter habitat) and phenotypic selection for other combinations of these traits. This lack of spatiotemporal consistency suggests that the strength and direction of selection on size and age at settlement (1) was not influenced by shelter availability; (2) differed among sites or years due to unmanipulated selective pressures; and/or, (3) affected traits that we did not measure in this study (e.g., lipid reserves). Spatiotemporal differences in patterns of selective mortality are only now becoming appreciated in the reef fish literature (e.g., Hoey and McCormick 2004, Holmes and McCormick 2006, McCormick and Meekan 2007, Vigliola et al. 2007), though such variation has been widely recognized elsewhere for some time (e.g., Grant and Grant 2002).

Although shelter availability per se did not create obvious differences in patterns of selective mortality, our manipulation altered the interaction between adult and juvenile goldspot gobies. The combination of lower shelter availability and higher adult densities strengthened density dependence and reduced juvenile survival, suggesting that adult density may act as an agent of selection in these populations (Endler 1986, Sogard 1997). Indeed, we found that selection favored larger juveniles in locations where adult densities were high and smaller juveniles in locations where adult densities were low. This relationship was primarily driven by the pattern within the high-shelter treatment where adult populations increased in response to the addition of potential refuges. Bigger juveniles may have been selectively favored because they were better able to compete with smaller juveniles and highly abundant adults for refuges. Previous studies support this possibility, as smaller juvenile reef fishes often lose disputes with conspecifics when competitive interactions occur
(Shulman 1985, Forrester et al. 2006) and are relegated to areas of habitat where predation risk is greater (Schmitt and Holbrook 1999, Webster 2004). In the lowshelter treatment, by contrast, the opportunity for phenotypic selection may have been reduced because the majority of juveniles of all phenotypes were unable to obtain refuges during predation events, leading to high but nonselective mortality. Other investigators have proposed that whether bigger- or smaller-is-better may depend on predator species composition (Holmes and McCormick 2006, McCormick and Meekan 2007) or other sources of environmental variation (Litvak and Legget 1992, Gagliano et al. 2007). It is not clear why selection intensity on larval traits other than size at settlement was unrelated to adult goby density.

The results of this study indicate that the availability of enemy-free space mediates interactions between adult and juvenile goldspot gobies. Higher adult densities were correlated with lower survival of juveniles, especially in locations where we did not experimentally augment refuge availability. Juvenile growth was negatively related to adult goby density in both low- and highshelter treatments. We also demonstrated a shift in both the direction and intensity of size-selective mortality that was correlated with the density of adult conspecifics. Selection favored larger juveniles in locations with high adult densities, but favored smaller juveniles at sites with low adult densities. These findings add to a growing appreciation for the importance of age-class interactions (Jones 1987, Schmitt and Holbrook 1999, Webster and Hixon 2000, Webster 2004, Wilson 2005), refuge availability (Holbrook and Schmitt 2002, Forrester and Steele 2004), and selective processes (Sogard 1997, Searcy and Sponaugle 2001, Hoey and McCormick 2004, Gagliano et al. 2007, McCormick and Meekan 2007, Vigliola et al. 2007, Hamilton et al. 2008) in driving the dynamics of marine fish populations.

\section{ACKNOWLEDGMENTS}

Many thanks to those who helped us with field work, including R. Gonzalez, W. Holden, D. King, T. Konotchick, J. Krug, K. Nickols, J. Noell, A. P. Parkin, L. Robinson, J. Stewart, A. Stier, M. Vasilakos, and A. Yau. We are also thankful to our laboratory assistants, including A. AlHumaidhi, N. Bulalacao, D. Danetra, R. Gonzalez, C. Griffith, L. Hayashi, K. Larsen, K. Le, A. Leonido, G. Nguyen, D. Storz, C. Tampoya, A. Villareal, and H. White. Excellent logistical support was provided by the staff at the Caribbean Marine Research Center (CMRC), and R. Warner graciously gave us access to terrific laboratory facilities. Ideas and comments from R. Calsbeek, S. Leslie Hamilton, P. Nosil, R. Vance, R. Warner, W. White, and the entire Warner laboratory greatly improved this research. Financial support was provided by an NSF pre-doctoral fellowship, and grants from the American Museum of Natural History, the American Society of Ichthyologists and Herpetologists, the International Women's Fishing Association, Sigma Xi, UC Regents, and the UCLA Department of Ecology and Evolutionary Biology to J. F. Samhouri, a NOAA-NURP grant to R. Vance and J. F. Samhouri (CMRC-05-PRRV-01-05A), and grants from NSF (OCE 0222087) and NOAA-NURP (CMRC-01-NRME-0103C, CMRC-03-NRME-01-04A, CMRC-03-NRME-01-05C) 
to G. E. Forrester, M. A. Steele, and R. Vance. View: $\rightarrow$ expressed herein are those of the authors and do not necessarily reflect those of PIMS, NOAA, or any of their sub-agencies.

\section{Literature Cited}

Altwegg, R., and H. U. Reyer. 2003. Patterns of natura- $\rightarrow$ selection on size at metamorphosis in water frogs. Evolution $57: 872-882$.

Anderson, C. S. 1995. Calculating size-dependent relative survival from samples taken before and after selection. Pages 455-466 in D. H. Secor, J. M. Dean, and S. E. Campana, editors. Recent developments in fish otolith research University of South Carolina Press, Columbia, South Carolina, USA.

Anderson, T. W., M. H. Carr, and M. A. Hixon. 2007. Patterns and mechanisms of variable settlement and recruitment of a coral reef damselfish, Chromis cyanea. Marine Ecology Progress Series 350:109-116.

Beckerman, A., T. G. Benton, E. Ranta, V. Kaitala, and P Lundberg. 2002. Population dynamic consequences or delayed life-history effects. Trends in Ecology and Evolution 17:263-269.

Bjornstad, O. N., J. M. Fromentin, N. C. Stenseth, and J. Gjosaeter. 1999. Cycles and trends in cod populations. Proceedings of the National Academy of Sciences (USA) 96:5066-5071.

Burnham, K. P., and D. R. Anderson. 2002. Model selection and multimodel inference. Second edition. Springer, New York, New York, USA.

Cameron, T. C., H. J. Wearing, P. Rohani, and S. M. Sait. 2007. Two-species asymmetric competition: effects of age structure on intra- and interspecific interactions. Journal of Animal Ecology 76:83-93.

$\rightarrow$ Carr, M. H., T. W. Anderson, and M. A. Hixon. 2002. Biodiversity, population regulation, and the stability of coral reef fish communities. Proceedings of the National Academy of Sciences (USA) 99:11241-11245.

Claessen, D., and U. Dieckmann. 2002. Ontogenetic niche shifts and evolutionary branching in size-structured populations. Evolutionary Ecology Research 4:189-217.

Crowley, P. H., P. M. Dillon, D. M. Johnson, and C. N. Watson. 1987. Intraspecific interference among larvae in a semivoltine dragonfly population. Oecologia 71:447-456.

de Roos, A. M., and L. Persson. 2003. Competition in sizestructured populations: mechanisms inducing cohort formation and population cycles. Theoretical Population Biology 63:1-16.

de Roos, A. M., L. Persson, and E. McCauley. 2003. The influence of size-dependent life-history traits on the structurc and dynamics of populations and communities. Ecology Letters 6:473-487.

$\rightarrow$ Edmunds, P. J., and R. Elahi. 2007. The demographics of a 15year decline in cover of the Caribbean reef coral Montastraea annularis. Ecological Monographs 77:3-18.

Eitam, A., L. Blaustein, and M. Mangel. 2005. Density and intercohort priority effects on larval Salamandra salamandra in temporary pools. Oecologia 146:36-42.

Endler, J. A. 1986. Natural selection in the wild. Princeton University Press, Princeton, New Jersey, USA.

Forrester, G. E. 1990. Factors influencing the juvenile demography of a coral-reef fish. Ecology 71:1666-1681.

Forrester, G. E. 1991. Social rank, individual size and group composition as determinants of food consumption b: humbug damselfish, Dascyllus aruanus. Animal Behaviour 42:701-711.

$\rightarrow$ Forrester, G. E., B. Evans, M. A. Steele, and R. R. Vance 2006. Assessing the magnitude of intra- and interspecific competition in two coral reef fishes. Oecologia 148:632-640.
Forrester, G. E., and M. A. Steele. 2004. Predators, prey refuges, and the spatial scaling of density-dependent prey mortality. Ecology 85:1332-1342.

$\rightarrow$ Fraser, D. F., and T. E. Sise. 1980. Observations on stream minnows in a patchy environment: a test of a theory of habitat distribution. Ecology 61:790-797.

Gagliano, M., M. I. McCormick, and M. G. Meekan. 2007. Survival against the odds: ontogenetic changes in selective pressure mediate growth-mortality trade-offs in a marine fish. Proceedings of the Royal Society London B 274:15751582 .

Grant, P. R., and B. R. Grant. 2002. Unpredictable evolution in a 30-year study of Darwin's finches. Science 296:707-711

Hamilton, S. L., J. Regetz, and R. R. Warner. 2008. Postsettlement survival linked to larval life in a marine fish. Proceedings of the National Academy of Sciences 105:15611566

Hamrin, S. F., and L. Persson. 1986. Asymmetrical competition between age classes as a factor causing population oscillations in an obligate planktivorous fish. Oikos 47:223-232.

Hixon, M. A., and G. P. Jones. 2005. Competition, predation, and density-dependent mortality in demersal marine fishes. Ecology 86:2847-2859.

Hixon, M. A., and M. S. Webster. 2002. Density dependence in reef fish populations. Pages $303-325$ in P. F. Sale, editor. Coral reef fishes: dynamics and diversity in a complex ecosystem. Academic Press, San Diego, California, USA.

Hoey, A. S., and M. I. McCormick. 2004. Selective predation for low body condition at the larval-juvenile transition of a coral reef fish. Oecologia 139:23-29.

Holbrook, S. J., and R. J. Schmitt. 2002. Competition for shelter space causes density-dependent predation mortality in damselfishes. Ecology 83:2855-2868.

Holmes, T. H., and M. I. McCormick. 2006. Location influences size-selective predation on newly settled reef fish. Marine Ecology Progress Series 317:203-209.

Jones, G. P. 1987. Competitive interactions among adults and juveniles in a coral-reef fish. Ecology 68:1534-1547.

Litvak, M. K., and W. C. Leggett. 1992. Age and size-selective predation on larval fishes: the bigger-is-better hypothesis revisited. Marine Ecology Progress Series 81:13-24.

Marshall, D. J., T. F. Bolton, and M. J. Keough. 2003. Offspring size affects the post-metamorphic performance of a colonial marine invertebrate. Ecology 84:3131-3137.

McCauley, E., and W. W. Murdoch. 1987. Cyclic and stablepopulations: plankton as paradigm. American Naturalist 129:97-121.

McCormick, M. I., and A. S. Hoey. 2004. Larval growth history determines juvenile growth and survival in a tropical marine fish. Oikos 106:225-242.

McCormick, M. I., and M. G. Meekan. 2007. Social facilitation of selective mortality. Ecology 88:1562-1570.

Murdoch, W. W. 1994. Population regulation in theory and practice. Ecology 75:271-287.

Parker, G. A., and W. J. Sutherland. 1986. Ideal free distributions when individuals differ in competitive ability: phenotype-limited ideal free models. Animal Behaviour 34: $1222-1242$.

Petranka, J. W. 1989. Density-dependent growth and survival of larval Ambystoma: evidence from whole-pond manipulations. Ecology 70:1752-1767.

Post, J. R., E. A: Parkinson, and N. T. Johnston. 1999. Densitydependent processes in structured fish populations: interaction strengths in whole-lake experiments. Ecological Monographs 69:155-175.

Relyea, R. A., and J. T. Hoverman. 2003. The impact of larval predators and competitors on the morphology and fitness of juvenile treefrogs. Oecologia 134:596-604.

Sandin, S. A., and S. W. Pacala. 2005. Fish aggregation results in inversely density-dependent predation on continuous coral reefs. Ecology 86:1520-1530. 
Scheiner, S. M. 2001. MANOVA: multiple response variable: $\rightarrow$ Steele, M. A., and G. E. Forrester. 2002. Early postsettlement and multispecies interactions. Pages $99-115$ in S. M. Scheiner and J. Gurevitch, editors. Design and analysis of ecological experiments. Oxford University Press, Oxford, UK.

$\rightarrow$ Schmitt, R. J., and S. J. Holbrook. 1999. Mortality of juvenile damselfish: implications for assessing processes that determine abundance. Ecology 80:35-50. predation on three reef fishes: effects on spatial patterns of recruitment. Ecology 83:1076-1091.

Szabo, A. R. 2002. Experimental tests of intercohort competition for food and cover in the tidepool sculpin (Oligocottus maculosus Girard). Canadian Journal of Zoology 80:137144.

Schroeter, S. C., T. A. Dean, K. Thies, and J. D. Dixon. 1995 Effects of shading by adults on the growth of blade-stage Macrosystis pyrifera (Phaeophyta) during and after the 19821984 El Niño. Journal of Phycology 31:697-702.

$\rightarrow$ Scott, D. E., E. D. Casey, M. F. Donovan, and T. K. Lynch. 2007. Amphibian lipid levels at metamorphosis correlate to post-metamorphic terrestrial survival. Oecologia 153:521532.

$\rightarrow$ Searcy, S. P., and S. Sponaugle. 2001. Selective mortality during the larval-juvenile transition in two coral reef fishes. Ecology 82:2452-2470.

Shulman, M. J. 1985. Coral-reef fish assemblages: intraspecific and interspecific competition for shelter sites. Environmental Biology of Fishes 13:81-92.

Sogard, S. M. 1997. Size-selective mortality in the juvenile stage of teleost fishes: a review. Bulletin of Marine Science 60: $1129-1157$.

Sponaugle, S., and R. K. Cowen. 1994. Larval durations and recruitment patterns of 2 Caribbean gobies (Gobiidae): contrasting early-life histories in demersal spawners. Marine Biology 120:133-143.

Vandenbos, R. E., W. M. Tonn, and S. M. Boss. 2006. Cascading life-history interactions: alternative density-dependent pathways drive recruitment dynamics in a freshwater fish. Oecologia 148:573-582.

Vigliola, L., P. J. Doherty, M. G. Meekan, D. M. Drown, M. E. Jones, and P. H. Barber. 2007. Genetic identity determines risk of post-settlement mortality of a marine fish. Ecology 88 : 1263-1277.

Vonesh, J. R., and O. De la Cruz. 2002. Complex life cycles and density dependence: assessing the contribution of egg mortality to amphibian declines. Oecologia 133:325-333.

Webster, M. S. 2004. Density dependence via intercohort competition in a coral-reef fish. Ecology 85:986-994.

Webster, M. S., and M. A. Hixon. 2000. Mechanisms and individual consequences of intraspecific competition in a coral-reef fish. Marine Ecology Progress Series 196:187-194. Wilson, J. A. 2005. Age class interactions in a marine goby, Elacatinus prochilos (Bohlke and Robins, 1968). Journal of Experimental Marine Biology and Ecology 327:144-156.

Winer, B. J., D. R. Brown, and K. M. Michels. 1991. Statistical principles in experimental design. McGraw-Hill, New York, New York, USA.

\section{APPENDIX A}

Map of the study sites and figures describing refuge availability, benthic cover, and spatial variation in goldspot goby (settler, survivor, and adult) and predator densities (Ecological Archives E090-065-A1).

\section{APPENDIX B}

Summary of model selection analysis comparing different measures of goldspot goby density as predictors of juvenile mortality rate (Ecological Archives E090-065-A2).

\section{APPENDIX C}

Comparison of goldspot goby larval traits for initial and survivor groups collected from low- and high-shelter habitats (Ecological Archives E090-065-A3). 